\title{
A guide to the internet for psychotherapists
}

One of the best collections of links to USA psychotherapy sites is at Mental Health Directory (http://www.mentalhealth.net). In the UK, two good starting points are: the Centre for Psychotherapeutic Studies at the University of Sheffield (http://www.shef.ac.uk/-psysc/) and Chris Evans' website (http://www. psyctc.org/).

The internet also offers many e-mail fora or discussion groups. The group interactions involved in fora have themselves attracted the attention of psychotherapists. Flaming, the net equivalent of group disruption, is discussed in detail at http://www. heenan. net/flame/ flame.html. InterPsych (http://www.interpsych.org/) currently hosts about 40 discussion groups including many that are concerned directly with psychotherapy. A list of other psychoanalytically orientated discussion groups can be found at http://www.shef.ac.uk/-psysc/. Deja news (http://www.deja.com) claims to host 80000 fora, including some on depression and deliberate selfharm. Deja news has long maintained one of the best indexes of usenet discussion groups and the site contains a search facility that will retrieve usenet messages containing a keyword.

Turning to the web, organisations, individuals, universities and special interest groups are all represented. The standard and presentation of material is improving all the time; near compact disc quality music (using the MP3 standard), good quality stills and video images, pictures from space, weather maps, real-time radio, chat, real-time TV and programmes too.

Psychotherapists need to be aware of these techniques. One outstanding example of what can be done is the posting by Stiles on the site of the Society for Psychotherapy Research (http://www.ted.educ.sfu.ca/society) of the audio recording of the cognitive--analytical therapy of 'Debbie'.

Finding academic colleagues is becoming easier as institutions are putting their phone books on to the web. The websites of all UK universities can be easily accessed from the UK sensitive map (http://www.scit.wlv.ac.uk/ ukinfo/uk.map.html) maintained by the University of Wolverhampton. Research collaborators for European projects can be advertised for at the European Commission's research website (http://www.cordis.lu/). More interesting is how to find the name of a suitable therapist in a specific location. Some of this information is known to the organisations that seek to regulate psychotherapy and therapeutic counselling in the UK. These include: United Kingdom Council for Psychotherapy (http:// www.psychotherapy.org.uk/index.html), the British Psychological Society (http://www.bps.org.uk) with its Division of Counselling Psychology and Section of Psychotherapy (http://www.bps.org.uk/sub-syst/ sections/gensect.htm//the), the British Association of Counselling (BAC) UK Register of Counsellors (http://www.counselling.co.uk), and the General
Medical Council (GMC) (http://www.gmc-uk.org/ standard/mainmenu.htm).

There are additional organisations that register practitioners, for example the British Confederation of Psychotherapy (psychoanalytic psychotherapists) (http:// www.bcp.org.uk) and the British Association of Behavioural and Cognitive Psychotherapy (http://www.babcp.org.uk). Both the GMC and BAC have e-mail enquiry forms on the internet. The GMC will only tell you about a particular doctor's status. The BAC will send lists of counsellors in the enquirer's area. None of the above organisations publish names on the web, although such lists have already developed in the USA. One example is the yellow pages (http://www.mentalhelp.net).

The European Association of Psychotherapy (http://www.europsyche.org) publishes the list of holders of the European Certificate of Psychotherapy on the web and on paper simultaneously. The list can be scanned by name, language, geographical location and theoretical orientation. However, not all psychotherapists are convinced that registration is the right means of selecting out competent and ethical practitioners. The arguments against can be read at http:// www. lpiper.demon.co.uk/carppp.htm.

A few guidelines can be obtained from the web, see http://www.strauss.ihs.ox.ac.uk/guidelines.html for a database of UK sites, but none that I know of relate to psychotherapy, although the BPS Centre for Outcomes Research and Effectiveness (CORE) (http:// www. psychol.ucl.ac.uk/CORE/home.html) is working on one for counselling and psychotherapy. CORE has already produced some mini-guides but is selling these rather than making them available on the web. Our own college seems to be putting parsimony before dissemination too, in not putting its guidelines concerning violence on the web.

An increasing number of journals are available on-line. The British Medical Journal (BMJ) (http:// www.bmj.com) is an example of excellence in this field because it also hosts discussions about articles. Recent psychotherapy-related articles have included one by Kisely \& Pelosis about the limited evidence for the effectiveness of psychotherapy in the treatment of severe personality disorders. Other relevant electronic journals include Psych News International (http:// www. mentalhelp.net/pni/pni4lc.htm). The journal Evidence-Based Mental Health at the Centre for Evidence-Based Mental Health (http://www.cebmh.com) is an excellent source of links into evidence-based practice, including psychotherapy. The contents pages of many psychology and social science journals can be searched collectively at http://www.shef.ac.uk./psysc/ journals/jsearch.html. Medline (http://www. biomednet.com/db/medline) and PsychLit indispensable source of research information. PsychLit is hard to access 
(8)

special articles without payment but a stripped down version, ClinPsych, is available to doctors who subscribe to CHAIN (http:// www.doh.gov.uk/ntrd/chain/about.htm). This is supported by the Department of Health (http:// www.doh.gov.uk/dhhome.htm).

Other resources that can be found on the net include: personality inventories (http:// www.ipip.ori.org/pip/index.htm); abstracts of Cochrane reviews (http://www.update-software.com/ccweb/ cochrane/edsr.htm) including a systematic review of debriefing and information about training courses in psychotherapy (e.g. http://www.shef.ac.uk/-psysc/ NSPC). The Government home page (http://www.open.gov.uk) has links to the Department of Health page and the Office of National Statistics at http:// www.ons.gov.uk, where information can be found from the most recent census.

Book publication on the net is in its infancy. However, a few classic texts of psychotherapy have been included in the massive Gutenberg project (http:// www.promo.net/pg). The only Freud book listed is a translation by Sigmund Freud of a 'Young Girl's Diary'. A directory of etexts is also available at http:// www. scc01. rutgers. edu/ceth/intromat/faq/faq6.html. However, the best way of finding the text of, say, the
Interpretation of Dreams, is to search for these words using a metasearch engine like Copernic 2000 (http:// www.copernic.com), which pulls in the results of searches using many engines. In this case a simple search found the 'Brill translation of the Interpretation of Dreams' at http://www. psychwww.com/books/interp/ toc.htm.

Psychotherapists might also be wise to prepare to carry out psychotherapy and supervision on the net. For an introduction to on-line psychotherapy and counselling in the USA, see http://www.metanoia.org/imhs/ index.html, and ask oneself, "Is this the shape of things to come?"

\section{Acknowledgements}

I am grateful to my partner, Emmy van Deurzen, for valuable comments. A longer version of this paper can be found at http://www.rcpsych.ac.uk/webguide/ psychoth/psychother.htm.

Digby Tantum Director, Centre for the Study of Violence and Reconciliation, University of Sheffield and Honorary Consultant Psychotherapist, Sheffield Community Health 